\title{
A tribute to Baruj Benacerraf
}

he community of immunologists mourns the recent passing of Baruj Benacerraf, one of the great pioneers of our field. He was rewarded for his seminal studies demonstrating genetic control of the immune response (along with George Snell and Jean Dausset) with the Nobel Prize in Physiology or Medicine in 1980. Baruj also made groundbreaking contributions to our understanding of the function of the reticular endothelial system, immunoglobulins, and the distinct characteristics of $\mathrm{T}$ and $\mathrm{B}$ lymphocyte recognition of antigen. In addition, Baruj was a remarkable leader who combined scientific insight with brilliant administrative skills.

Benacerraf's landmark scientific discovery came from his early experiments that revealed a genetic locus that controlled immune responses to simple antigens. $\mathrm{He}$ observed that some, but not all, randomly bred guinea pigs responded to antigens. This was the kind of equivocal observation that might be ignored by most scientists. He went on to show, through inbreeding experiments, that the ability to respond to antigen was determined by a genetic locus that acted in an autosomal dominant fashion. When these papers were published, George Snell, the eminent mouse geneticist, reportedly said that only a handful of scientists understood this work and fewer still appreciated its transformative nature. Benacerraf and his colleagues used these observations as an experimental foothold to further define a group of genes, termed immune response (Ir) genes, that controlled immune responses and went on to show that Ir genes were linked to the MHC and indeed coded for MHC molecules. These studies led to our present understanding of how $\mathrm{T}$ lymphocytes recognize antigen and continue to represent a cornerstone of our understanding of the immune response.

Numerous sources and recent tributes recount Benacerraf's life in detail, from his birth in 1920 in Caracas, upbringing in Paris, and US education, naturalization, and service during WWII to his struggle to attend medical school (1-3). One can begin to understand a bit more about this formidable yet unassuming man by appreciating his remarkable perseverance in the face of substantial obstacles early in his career. As an established scientist, Benacerraf continued to display the same perseverance in the laboratory and refused to ignore phenomena that many might discount or overlook.

One of Benacerraf's most lasting and valued contributions to immunology is his legacy of trainees. Beginning in 1956 and continuing for the next thirty years, Benacerraf trained over 80 postdoctoral fellows and graduate students.

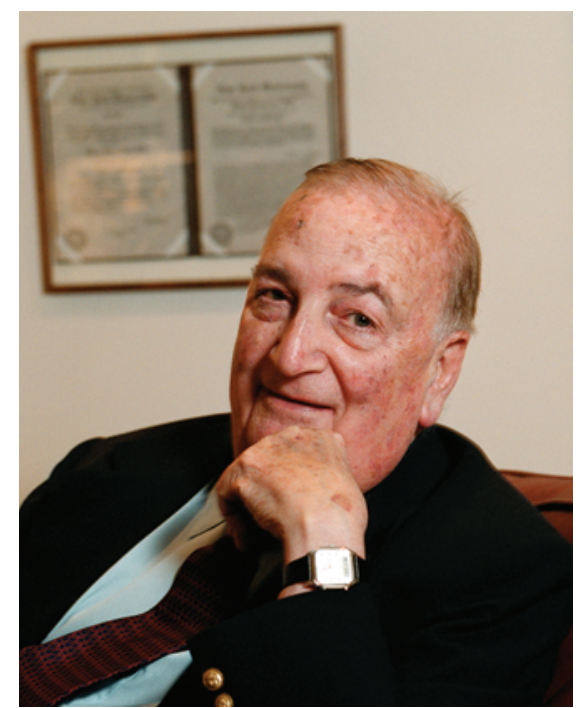

The majority of his former trainees now lead major research programs around the world, have made substantive contributions to the field, and continue to instill his approach to science to successive generations of scientists. In 1970, while at NIH, Benacerraf accepted the position of chair of pathology at Harvard Medical School, because he "missed the university environment and more particularly the stimulating interaction with the eager, enthusiastic, and unprejudiced young minds of the students and fellows" (1). Not long after his arrival, he founded a graduate program in immunology, the oldest degree-conferring graduate program at Harvard Medical School, which has served as a model for programs in cell biology and virology. The Benacerraf legacy at Harvard Medical School/DanaFarber Cancer Institute now includes more than 200 program in immunology students who have obtained degrees since
1971 as well as an annual lecture and an endowed chair in immunology, which I am honored to currently hold.

I first met Benacerraf as a fourth-year medical student at NYU, after requesting an appointment to discuss experimental data I had obtained working with Alan Dumont. Benacerraf was very kind but direct. He said, "Write it up, send it to Nature, and go to the NIH," which, as it happens, is exactly what I did. Our paths crossed again over the years, and I was fortunate enough to be at Dana-Farber when he assumed the presidency in 1980, just a few months before receiving the news that he had been awarded the Nobel Prize. His business acumen strengthened and stabilized the institute and fostered an era of unprecedented growth and discovery using immunology-based approaches, such that we are now in a position to more effectively mobilize the immune system against diseases, including cancer.

While Baruj's scientific achievements were remarkable, he drew equal satisfaction from his role as mentor to young immunologists. In a recent interview celebrating the 30th anniversary of his receipt of the Nobel Prize, Benacerraf reflected on his discoveries and personal traits that shaped his life: "When people came to work with me, I told them that research is simply a challenge to find the truth. You have to be moved and try and try again. Don't accept what exists already as final. If you derive pleasure from that, you're a scientist" (4).

\section{Harvey Cantor}

Harvard Medical School, Chair, Department of Cancer Immunology and AIDS, Dana-Farber Cancer Institute, 450 Brookline Avenue, Boston, Massachusetts 02215, USA. Phone: 617.632.3348; Fax: 617.632.4630; E-mail: Harvey_Cantor@ dfci.harvard.edu.

\footnotetext{
1. Benacerraf B. Autobiography. In: Odelberg W, ed. The Nobel Prizes 1980. Stockholm, Sweden: Nobel Foundation; 2011.

2. Germain R, Burakoff SJ. A Remembrance of Baruj Benacerraf (AAI '57), 1920-2011. The American Association of Immunologists web site. http:// www.aai.org/News_Board/2011/Benacerraf/AAI_ Remembrance.htm. Accessed September 20, 2011.

3. Letvin NL. Baruj Benacerraf(1921-2011). Immunity. 2011;35(2):147-148.

4. Levy R. Setting a new standard: how Baruj Benacerraf turned modern immunology on its head. Paths of Progress. 2010;19(1):16-19.
} 